\title{
Mining for sensitive and reliable species-specific primers for PCR for detection of Cronobacter sakazakii by a bioinformatics approach
}

\author{
Chen Qiming, ${ }^{*}$ Tao Tingting, ${ }^{*}$ Bie Xiaomei, ${ }^{*}$ Lu Yingjian,† Lu Fengxia, ${ }^{*}$ Zhai Ligong, ${ }^{*}$ and Lu Zhaoxin ${ }^{* 1}$ \\ ${ }^{*}$ College of Food Science and Technology, Nanjing Agricultural University, 1 Weigang, Nanjing 210095, People's Republic of China \\ †Department of Nutrition and Food Sciences, University of Maryland, College Park 20742
}

\begin{abstract}
Although several studies have reported PCR assays for distinguishing Cronobacter sakazakii from other species in the genus, reports regarding assay sensitivity and specificity, as well as applications for food testing, are lacking. Hence, the objective of this study was to develop a sensitive and reliable PCR-based method for detection of $C$. sakazakii by screening for specific target genes. The genome sequence of $C$. sakazakii in the GenBank database was compared with that of other organisms using BLAST. Thirty-eight DNA fragments unique to C. sakazakii were identified, and primers targeting these sequences were designed. Finally, 3 primer sets (CS14, CS21, and CS38) were found to be specific for C. sakazakii by PCR verification. The detection limit of PCR assays using the 3 pairs of primers was $1.35 \mathrm{pg} / \mu \mathrm{L}, 135 \mathrm{fg} / \mu \mathrm{L}$, and $135 \mathrm{fg} / \mu \mathrm{L}$, respectively, for genomic DNA, and $5.5 \times 10^{5}, 5.5 \times 10^{3}, 5.5 \times 10^{3} \mathrm{cfu} /$ $\mathrm{mL}$, respectively, using pure cultures of the bacteria, compared with $13.5 \mathrm{pg} / \mu \mathrm{L}$ and $5.5 \times 10^{5} \mathrm{cfu} / \mathrm{mL}$ for primer set SpeCronsaka, which has been previously described. Cronobacter sakazakii were detected in artificially contaminated powdered infant formula (PIF) by PCR using primer sets CS21 and CS38 after $8 \mathrm{~h}$ of enrichment. The detection limit was $5.5 \times 10^{-1} \mathrm{cfu} / 10$ $\mathrm{g}$ of PIF. Thus, the PCR assay can be used for rapid and sensitive detection of C. sakazakii in PIF.
\end{abstract}

Key words: Cronobacter sakazakii, PCR detection, powdered infant formula, species-specific primers

\section{INTRODUCTION}

Cronobacter sakazakii is a gram-negative pathogen that can cause necrotizing enterocolitis, sepsis, and meningitis in all age groups (Iversen et al., 2008; Li et al., 2012). The fatality rate of infections caused by C. sakazakii can be 50 to $80 \%$ (Townsend et al., 2008; Healy et al., 2010). Thus, the International Commis-

Received January 3, 2015.

Accepted April 24, 2015.

${ }^{1}$ Corresponding author: fmb@njau.edu.cn sion for Microbiological Specifications for Foods (ICMSF) ranked Cronobacter spp. as a "severe hazard for restricted populations, life threatening or substantial chronic sequelae or long duration" (Hoque et al., 2010). Cronobacter spp., mostly C. sakazakii, can be isolated from a wide range of food sources (Friedemann, 2007; Joseph and Forsythe, 2012); however, many infections caused by this opportunistic pathogen have been epidemiologically linked to contaminated powdered infant formula (PIF; Muytjens et al., 1983; Arseni et al., 1987; Simmons et al., 1989; Ray et al., 2007; Li et al., 2014).

Methods based on PCR have been widely used for detection of pathogens because they are simple and rapid compared with conventional culture-based methods. Several targets have been described for PCR detection of Cronobacter genus, including 16S ribosomal (r)DNA (Iversen et al., 2004), 16S-23S rDNA internal transcribed spacer (Liu et al., 2006), 23S rDNA (Derzelle et al., 2007), transfer (t)RNAGlu (Hassan et al., 2007), dnaG (Seo and Brackett, 2005), ompA (Mohan Nair and Venkitanarayanan, 2006), gluA (Iversen et al., 2007), wehC, wehI (Mullane et al., 2008), wzx (Jarvis et al., 2011), zpx (Jaradat et al., 2009), and others.

Only 3 species of Cronobacter (C. sakazakii, $C$. malonaticus, and C. turicensis) have been associated with human infection. The virulence of these pathogens differs, and C. sakazakii causes the majority of serious neonatal and infant infections (Jackson et al., 2014; Zimmermann et al., 2014). Very few reports have described PCR assays for detection of C. sakazakii; thus, it is critical to develop methods targeting this important species of Cronobacter. The first gene used as a target for the identification of the 6 Cronobacter species was rpoB (Stoop et al., 2009). The disadvantage of this target was that $2 \mathrm{PCR}$ amplification reactions were needed to identify $C$. sakazakii and distinguish it from other species. In another report, the sequence of the $c g c A$ gene was analyzed to design primers that were specific to C. sakazakii, and only one PCR amplification reaction was needed. However, a problem with this assay was that nonspecific bands appeared when the PCR products were analyzed on agarose gels (Carter et al., 2013). The gyrB gene has also been used as a 
molecular marker to design primers that are specific to C. sakazakii (Huang et al., 2013). All primers could be used for detecting $C$. sakazakii and distinguishing it from other species in the Cronobacter genus; however, the sensitivity of the assays, interference due non- $C$. sakazakii bacteria, and PCR assays for testing of food were not reported.

Because of advancements in next-generation sequencing technologies, the genome sequences of a large number of organisms are currently available in the National Center for Biotechnology Information (NCBI) GenBank database (http://www.ncbi.nlm. nih.gov/genbank/). Utilizing the genome sequence data and tools provided by NCBI, molecular targets specific for different pathogens can be obtained easily. For the Cronobacter genus, the genome sequences of 2 species (C. sakazakii and C. turicensis) are available, and sequencing of additional strains is in progress. The objective of this work was to identify molecular targets that are specific to C. sakazakii by analyzing the genome sequence of C. sakazakii ATCC BAA-894. Primers targeting these DNA fragments were then designed and evaluated. Finally, a new PCR method for the detection of C. sakazakii in food was developed.

\section{MATERIALS AND METHODS}

\section{Bacterial Strains}

A total of 12 Cronobacter strains and 26 non-Cronobacter strains (Table 1) were used in this study. They were purchased from the China Center of Industrial Culture Collection (CICC, Beijing, China), the National Center for Medical Culture Collections (CMCC, Beijing, China), the American Type Culture Collection (ATCC, Manassas, VA), the China General Microbiological Culture Collection Center (CGMCC, Beijing, China), the National Collection of Type Cultures (NCTC, Salisbury, UK), and the Deutsche Sammlung von Mikroorganismen und Zellkulturen (DSMZ, Braunschweig, Germany). The other strains that were used were part of our laboratory culture collection (Table 1). All strains were retrieved from frozen stock cultures and grown in appropriate broth at $37^{\circ} \mathrm{C}$, at $180 \mathrm{rpm}$, and in common air.

\section{Selection of C. sakazakii-Specific Targets}

Information on the complete genome sequence of $C$. sakazakii ATCC BAA-894 (GenBank accession number: CP000783.1) was obtained from GenBank (http:// www.ncbi.nlm.nih.gov/genbank). The genome of $C$. sakazakii ATCC BAA-894 includes 4,562 genes and 4,422 coding sequences. All of the gene sequences were compared with those of other bacteria in the nucleotide database (nucleotide collection) using the Basic Local Alignment Search Tool (BLAST; http://blast.ncbi. nlm.nih.gov/Blast.cgi). The coding sequence in the genome of C. sakazakii ATCC BAA-894 that matched with those of all 4 strains of C. sakazakii (GenBank accession ID: CP000783.1, CP003312.1, CP004091.1 and CP006731.1) with completed genome sequences and that could not be found in other organisms were chosen as candidate targets for detection.

\section{DNA Preparation}

All strains of bacteria were cultured in Luria-Bertani (LB) broth at $37^{\circ} \mathrm{C}$. The bacterial cultures were then collected by centrifugation at $12,000 \times g$ for $5 \mathrm{~min}$. Genomic DNA from these cells was extracted and purified using the E.N.Z.A Bacteria Genome kit (Omega Bio-Tek Inc., Norcross, GA) according to the manufacturer's instructions. The concentration and purity of the DNA were estimated by agarose gel electrophoresis and by using the NanoDrop 2000c UV-Vis spectrophotometer (Thermo Fisher Scientific, Waltham, MA). In addition, crude genomic DNA extracts were prepared by boiling cells in sterile water. Cell pellets obtained by centrifugation were resuspended in $200 \mu \mathrm{L}$ of sterile distilled water, boiled for $10 \mathrm{~min}$, stored at $-20^{\circ} \mathrm{C}$ for $10 \mathrm{~min}$, and then centrifuged at $12,000 \times g$ for $5 \mathrm{~min}$. The supernatant with crude DNA was used as template in $\mathrm{PCR}$ reactions.

\section{PCR Conditions}

The PCR was carried out in a $25-\mu \mathrm{L}$ reaction mixture, which consisted of $12.5 \mu \mathrm{L}$ of $2 \times$ Taq Master (Vazyme Biotech Co., Jiangsu, China), $9.5 \mu \mathrm{L}$ of sterile distilled water, $1 \mu \mathrm{L}$ of each primer at a concentration of 0.25 $\mu M$, and $1 \mu \mathrm{L}$ of genomic DNA. The PCR cycling conditions included an initial incubation at $95^{\circ} \mathrm{C}$ for $5 \mathrm{~min}$, followed by 30 cycles of $95^{\circ} \mathrm{C}$ for $40 \mathrm{~s}, 60^{\circ} \mathrm{C}$ for $30 \mathrm{~s}$, $72^{\circ} \mathrm{C}$ for $30 \mathrm{~s}$, and the final extension of $72^{\circ} \mathrm{C}$ for 10 min. To compare the primers designed in the current study with primers reported previously targeting gyrB, primer set SpeCronsaka (SpeCronsaka-F1: AGG TAA AAT CCA CCA GCA AAC; SpeCronsaka-R1: CAG AAT ATC GTA TTC AAA CTC; Huang et al., 2013) was used as a control. The PCR mixture was the same as described above, and the cycling protocol consisted of 1 cycle at $94^{\circ} \mathrm{C}$ for $5 \mathrm{~min}$, followed by 30 cycles of $94^{\circ} \mathrm{C}$ for $1 \mathrm{~min}, 62^{\circ} \mathrm{C}$ for $1 \mathrm{~min}$, and $72^{\circ} \mathrm{C}$ for $1 \mathrm{~min}$, and a final extension at $72^{\circ} \mathrm{C}$ for $7 \mathrm{~min}$. Purified genomic DNA from C. sakazakii CICC21560 extracted with the commercial kit and sterile distilled water were used as the positive and negative controls in the PCR, respec- 
Table 1. Bacterial strains and PCR results (positive, +, or negative, -) obtained in the this study

\begin{tabular}{|c|c|c|c|c|}
\hline \multirow[b]{2}{*}{ Bacterial strain } & \multirow{2}{*}{$\begin{array}{l}\text { Strain } \\
\text { identification }^{1}\end{array}$} & \multicolumn{3}{|c|}{$\begin{array}{l}\text { PCR results using } \\
3 \text { primer sets }{ }^{1}\end{array}$} \\
\hline & & CS14 & CS21 & CS38 \\
\hline \multicolumn{5}{|l|}{ Cronobacter strains } \\
\hline C. malonaticus & DSM18702 & - & - & - \\
\hline C. turicensis & DSM18703 & - & - & - \\
\hline C. dublinensis & DSM18705 & - & - & - \\
\hline C. sakazakii & CICC21560 & + & + & + \\
\hline C. sakazakii & Food isolate $^{2}$ & + & + & + \\
\hline C. sakazakii & Food isolate $^{2}$ & + & + & + \\
\hline C. sakazakii & Food isolate $^{2}$ & + & + & + \\
\hline C. sakazakii & Food isolate $^{2}$ & + & + & + \\
\hline C. sakazakii & Food isolate $^{2}$ & + & + & + \\
\hline C. sakazakii & Food isolate $^{2}$ & + & + & + \\
\hline C. muytjensii & CICC21563 & - & - & - \\
\hline C. universalis & NCTC9529 & - & - & - \\
\hline \multicolumn{5}{|l|}{ Non-Cronobacter strains } \\
\hline Salmonella Brenderup & ATCCH9812 & - & - & - \\
\hline Salmonella Saintpaul & CICC21486 & - & - & - \\
\hline Salmonella Kentucky & CICC21488 & - & - & - \\
\hline Salmonella Blockley & CICC21489 & - & - & - \\
\hline Salmonella Bonariensis & CICC21527 & - & - & - \\
\hline Salmonella Wandsworth & CICC21504 & - & - & - \\
\hline Salmonella Adelaide & CICC21505 & - & - & - \\
\hline Salmonella Enteritidis & CICC21482 & - & - & - \\
\hline Salmonella Typhimurium & CMCC56041 & - & - & - \\
\hline Listeria monocytogenes & CICC21662 & - & - & - \\
\hline Listeria monocytogenes & CICC21634 & - & - & - \\
\hline Staphylococcus aureus & ATCC29213 & - & - & - \\
\hline Enterobacter cloacae & ATCC13047 & - & - & - \\
\hline Micrococcus luteus & Laboratory strain & - & - & - \\
\hline Bacillus pumilus & CMCC63202 & - & - & - \\
\hline Escherichia coli & CICC23657 & - & - & - \\
\hline Escherichia coli $\mathrm{O} 157$ & CICC21530 & - & - & - \\
\hline Escherichia coli DH5 $\alpha$ & Laboratory strain & - & - & - \\
\hline Escherichia coli BL21 & Laboratory strain & - & - & - \\
\hline Pseudomonas fluorescens & AS1.1802 & - & - & - \\
\hline Bacillus cereus & AS1.1846 & - & - & - \\
\hline Bacillus subtilis & Laboratory strain & - & - & - \\
\hline Vibrio parahaemolyticus & ATCC 33847 & - & - & - \\
\hline Yersinia enterocolitica & CMCC 52225 & - & - & - \\
\hline Bacillus licheniformis & CICC 23584 & - & - & - \\
\hline Serratia marcescens & CICC 10187 & - & - & - \\
\hline
\end{tabular}

${ }^{1}$ Strains were purchased from the China Center of Industrial Culture Collection (CICC, Beijing, China), the National Center for Medical Culture Collections (CMCC, Beijing, China), the American Type Culture Collection (ATCC, Manassas, VA), the China General Microbiological Culture Collection Center (CGMCC, Beijing, China), the National Collection of Type Cultures (NCTC, Salisbury, UK), and the Deutsche Sammlung von Mikroorganismen und Zellkulturen (DSMZ, Braunschweig, Germany).

${ }^{2}$ Laboratory strains isolated from food samples.

tively. The PCR products were analyzed by agarose gel electrophoresis using the $D S^{\mathrm{TM}} 2000$ DNA markers (Dongsheng Biotechnology, Guangdong, China) and visualized using a UV transilluminator.

\section{Primer Design}

Primer Premier 5.0 software (Premier Biosoft International, Palo Alto, CA) was used to design primers targeting the sequences of the C. sakazakii-specific DNA fragments described in the section Selection of $C$.
sakazakii-Specific Targets. The primers with the highest rating score were chosen. All primers were synthesized by Shanghai Sangon Company (Shanghai, China).

\section{Primers Selection Based on Their Specificity}

Primers described above were tested using genomic DNA from C. sakazakii CICC21560 as template. The primers that generated a strong, single band were selected for further testing. To select primers that were specific to C. sakazakii, 6 C. sakazakii laboratory strains 
isolated from food samples, 5 other laboratory strains of Cronobacter spp., and 26 strains of non-Cronobacter bacteria (Table 1) were used as targets for testing the specificity of the primers. The primers that generated negative results with non- $C$. sakazakii bacteria were considered specific primers, and these were evaluated to develop PCR detection methods.

\section{Sensitivity Evaluation of Specific Primers Using Genomic DNA}

Purified DNA of known concentration extracted from C. sakazakii CICC21560 was serially diluted 10-fold. One microliter of the DNA from each dilution was used as template in a $25-\mu \mathrm{L}$ PCR reaction. The PCR results were analyzed, and the detection limit of the PCR was determined.

\section{Sensitivity Evaluation of Specific Primers Using Whole Cells}

Cronobacter sakazakii CICC21560 was cultured in LB broth at $37^{\circ} \mathrm{C}$ overnight. The cell culture was serially diluted 10 -fold with $0.9 \%$ normal saline (when the cell concentration reached $10^{2} \mathrm{cfu} / \mathrm{mL}$, the 10 -fold dilution turned into doubling dilution) and the cell concentration was determined by plating onto LB agar and counting the colonies. Crude DNA from the different dilutions was extracted by heating $1 \mathrm{~mL}$ of the dilutions at $100^{\circ} \mathrm{C}$ for $10 \mathrm{~min}$. One microliter of crude DNA from each cell concentration was used as template in the PCR assays. The PCR results were analyzed and the detection limit was obtained.

\section{Testing for PCR Interference with Various Concentrations of Escherichia coli}

Cronobacter sakazakii CICC21560 and E. coli CMCC23657 were cultured in LB broth at $37^{\circ} \mathrm{C}$ overnight. The cell concentrations were determined by plating 10 -fold serial dilutions prepared in $0.9 \%$ normal saline. Serial dilutions (10-fold) were prepared to obtain E. coli CMCC23657 at different cell concentrations, ranging from $10^{8}$ to $10^{0} \mathrm{cfu} / \mathrm{mL}$ (when the cell concentration reached $10^{2} \mathrm{cfu} / \mathrm{mL}$, the 10 -fold dilution turned into doubling dilution). Cronobacter sakazakii was used at a fixed concentration of $10^{7} \mathrm{cfu} / \mathrm{mL}$. The E. coli cells at different concentrations and C. sakazakii cells at a fixed concentration were mixed in equal volumes. Then, DNA was extracted from the cell mixtures by heating at $100^{\circ} \mathrm{C}$ for $10 \mathrm{~min}$ and was used as template for the PCR. The PCR products were analyzed by gel electrophoresis and visualized using a UV transilluminator.

\section{Use of the PCR Assay to Detect C. Sakazakii in Artificially Inoculated PIF}

Cronobacter sakazakii CICC21560 was cultured in LB broth at $37^{\circ} \mathrm{C}$ for $12 \mathrm{~h}$, and the cell concentration was estimated by plate counting. One milliliter of the cell cultures at concentrations of $10^{1}, 10^{0}$, and $10^{-1} \mathrm{cfu} /$ $\mathrm{mL}$ were each mixed with $10 \mathrm{~g}$ of PIF, and these were each added to $89 \mathrm{~mL}$ of $\mathrm{LB}$ medium and incubated at $37^{\circ} \mathrm{C}$. One milliliter of sterile distilled water in 10 $\mathrm{g}$ of PIF was used as a control check. From 0 to $12 \mathrm{~h}$, 1-mL aliquots of the samples were taken every $2 \mathrm{~h}$ and stored at $-20^{\circ} \mathrm{C}$. Genomic DNA from the samples was extracted by heating at $100^{\circ} \mathrm{C}$ for $10 \mathrm{~min}$ and used as template in PCR assays.

\section{RESULTS AND DISCUSSION}

\section{Screening of C. Sakazakii-Specific Targets for Detection}

Based on previous reports, the primers used in PCR assays to distinguish C. sakazakii from other species only targeted the $r p o B$, gyrB, and $c g c A$ genes (Stoop et al., 2009; Carter et al., 2013; Huang et al., 2013). The sensitivity of these assays and the effect of interference from other bacteria were not reported. Furthermore, the performance of these primers in PCR assays with actual food samples is not known. Hence, there is a need to identify additional specific targets for C. sakazakii and to develop sensitive and specific PCR assays for detection of the pathogen in food. In this study, a bioinformatics approach was used to identify as many specific targets as possible for C. sakazakii. The complete genome sequence of $C$. sakazakii ATCC BAA-944 was chosen to identify specific DNA fragments. Thirty-eight DNA fragments were identified as described above and found only in the 4 C. sakazakii strains as determined using the BLAST program on the NCBI website, and therefore, these were chosen as candidate targets. The 38 DNA fragments and their respective gene IDs are shown in Table 2.

\section{Determination of Primers Specific for C. sakazakii}

The primers for the PCR assays were designed according to the sequences of the 38 DNA fragments. Three primer sets, numbers 14, 21, and 38, produced strong, single bands for C. sakazakii CICC21560 and 6 other C. sakazakii isolates, but no bands with 5 strains belonging to other Cronobacter species and 22 nonCronobacter strains (Tables 1 and 2). Only 3 out of 38 $(7.89 \%)$ primer sets showed perfect specificity in PCR assays and the others generated nonspecific products, 
Table 2. Primer sets used in PCR assays for Cronobacter sakazakii and their target genes

\begin{tabular}{|c|c|c|c|c|c|c|}
\hline Gene ID & Location & Primer & Forward primer $\left(5^{\prime} \rightarrow 3^{\prime}\right)$ & Reverse primer $\left(5^{\prime} \rightarrow 3^{\prime}\right)$ & $\begin{array}{l}\text { C. sakazakii } \\
\text { specific }^{1}\end{array}$ & $\begin{array}{l}\text { Product } \\
\text { (bp) }\end{array}$ \\
\hline ESA_01316 & 1273202-1273804 & 1 & GAAGAACTCAAAGCACGCATAA & CCACGCCGTAGATTTCATAC & - & 386 \\
\hline ESA_01404-ESA_01406 & 1357289-1357618 & 2 & AAGAGTTTGCGTGAAGCG & TCTGCCTACCTGATGGAGTT & - & 218 \\
\hline ESA_01600 & 1553679-1554035 & 3 & AGGGCGTTTGTGCGGGTAT & CGGCAAGTTCGGCATCCA & - & 219 \\
\hline ESA_01690 & 1631811-1632131 & 4 & CCTGCTGGTCGTGATGCTG & GCTTCTGCCCTGCCATTTT & - & 247 \\
\hline ESA_01813-ESA_01814 & $1751551-1752024$ & 5 & TGCTGAATGCTGACGGCTCT & GGCTGATAAGGCGCAAACG & - & 223 \\
\hline ESA_01842-ESA_01844 & $1785425-1785757$ & 6 & TTCGGCAAACCTGAACTG & CCACGCTAAATGTCGTAAAA & - & 109 \\
\hline ESA_01846-ESA_01847 & $1787361-1788356$ & 7 & ACGTTACGCTGCATGGTCC & GCGGCGGTTATCAACAAGAG & - & 329 \\
\hline ESA_01854-ESA_01855 & 1793571-1793861 & 8 & CGTGCGGCAGGCTTTCTT & CTTCGGCTGGCTGATGGA & - & 141 \\
\hline ESA_01864 & 1799525-1799917 & 9 & CGGGTGGTGACATAGGTAAA & GCTCGGCGTGGTAGAAAC & - & 171 \\
\hline ESA_01917-ESA_01918 & 1851961-1852797 & 10 & TTCGCCAAGAAGAATCAACG & CTATTTAGCGCAAACGGTAGTG & - & 196 \\
\hline ESA_01953 & $1886711-1887226$ & 11 & GTTATCGCTGATGAACAGTCGC & GATGGCATGGCACCACAAT & - & 370 \\
\hline ESA_02004-ESA_02005 & 1942675-1943193 & 12 & CCAGCGGTTTCGGATGAT & TGGTGACTGACAAAGGCGTAG & - & 399 \\
\hline ESA_02129 & 2077070-2077579 & 13 & AGGGTCTCGTCCGCTTTC & GCTGCTGGTTGCATTTCC & - & 452 \\
\hline ESA_02130 & $2077786-2078235$ & 14 & GCCCAGACTTTGATCTCC & TCATTCCCGCTGACTATTT & + & 148 \\
\hline ESA_02197 & 2133810-2134192 & 15 & CGGTGTAATAACGGGTGTC & GGCGGATAGGGTGATAAA & - & 152 \\
\hline ESA_02199 & $2136757-2137560$ & 16 & GGTGGGAGCCGTTGAATA & ACAGGAAGTGCCAGGAGG & - & 282 \\
\hline ESA_02372 & $2305278-2306234$ & 17 & TGTCGGATAGTTGCGGTTGT & CGGTGGTAAAGAGGATTTCG & - & 247 \\
\hline ESA_02487 & $2435050-2435367$ & 18 & CAGAGCGAGCCGATAGAGC & AGACGGGGCCGTGAACTT & - & 158 \\
\hline ESA_02538 & 2490652-2491191 & 19 & GCTCCTCCTCGCTCACAT & AGGCTTTGGTCACGGTTT & - & 225 \\
\hline ESA_02544 & $2498505-2499350$ & 20 & CGCGGCCAGGAAGTGATT & TCGGCGAGCGTGACATAA & - & 245 \\
\hline ESA_02797 & $2745128-2747617$ & 21 & GGCAGCATGTCATTATCGG & CATCAGTGGCATTCGGTCTA & + & 152 \\
\hline ESA_02799 & $2748430-2748966$ & 22 & ATCCGTATTACCGTCGTTC & ССАТСАСССТTТСТТССТG & - & 185 \\
\hline ESA_03005-ESA_03006 & $2958749-2959192$ & 23 & GCAGCGAGTGTCTGGAAG & CGCACCGAGAAAGTGAGTA & - & 239 \\
\hline ESA_03007 & 2959236-2959697 & 24 & GAACTCGCTCCCTGCTTT & CTCATCGTCACGCCTCCA & - & 188 \\
\hline ESA_03008 & 2959764-2960207 & 25 & CGAAGCCGAACTCAAACA & CGGTAGGTCAGCCAGTCA & - & 147 \\
\hline ESA_03009 & $2960351-2960794$ & 26 & ATGGCTTAAATATCGTGATG & CCAGGCTCGTTATGTGAA & - & 149 \\
\hline ESA_03010 & 2960874-2961338 & 27 & CCCAGTCTTCATAGCCCTCC & CGCAGATGCTGAGCCACTA & - & 174 \\
\hline ESA_03321 & $3256913-3257251$ & 28 & CATGTTGCGGTCAATAGC & TGATGAAGCGTGAAAGAAA & - & 116 \\
\hline ESA_03358 & $3298780-3299445$ & 29 & CATCAATGGCATCATCAACA & GTCGCACAATCTCCACTCAC & - & 104 \\
\hline ESA_03490-ESA_03491 & $3436595-3437245$ & 30 & CGGTCAATATCAATTATCAGCA & ACAGCAGCAGTTCGTGGC & - & 177 \\
\hline ESA_03743 & $3683541-3683936$ & 31 & TTAAGCGACAAGTGGAAA & GACAGGCGAAATAGAACG & - & 292 \\
\hline ESA_03887 & 3838625-3839092 & 32 & CGACCGTAATCGCTTGCT & CGCTTCCCATTGAAACAC & - & 154 \\
\hline ESA_03999-ESA_04000 & 3946069-3946689 & 33 & GCTGAAGGGCTTTGGTATG & CTATCTGGCTGGTATTGCTGA & - & 291 \\
\hline ESA_04072 & 4024815-4025576 & 34 & TGGAGTATGTTTGAGCGTGTA & AAGATTTGCCCTTTGTGG & - & 431 \\
\hline ESA_04112 & 4068989-4069789 & 35 & TGGCATTACGCCGCATTT & AGCGACGGACGCACTTTT & - & 450 \\
\hline ESA_04152 & 4104173-4104634 & 36 & AACCTATGGTGGTGGACT & GATCTGACTTTCAATTTCG & - & 256 \\
\hline ESA_04314-ESA_04315 & $4279292-4279753$ & 37 & TCTGGGCGGTGCTTGTCT & GGCGGCGTCCGTAATAAA & - & 219 \\
\hline ESA_04347-ESA_04349 & $4318202-4318678$ & 38 & CGGGTTACGCAGGGTTGA & GCGGTTGCCAGTGAATAAGAT & + & 222 \\
\hline
\end{tabular}

$\lesssim \quad{ }^{1+}=$ a strong, single band was obtained using the primers in the PCR assay; - = no band was visible when the primers were used in the PCR assay. 


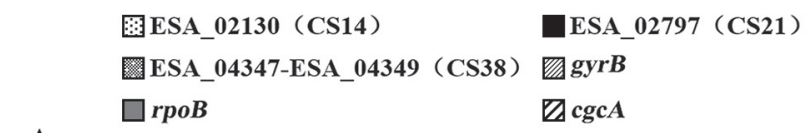

A

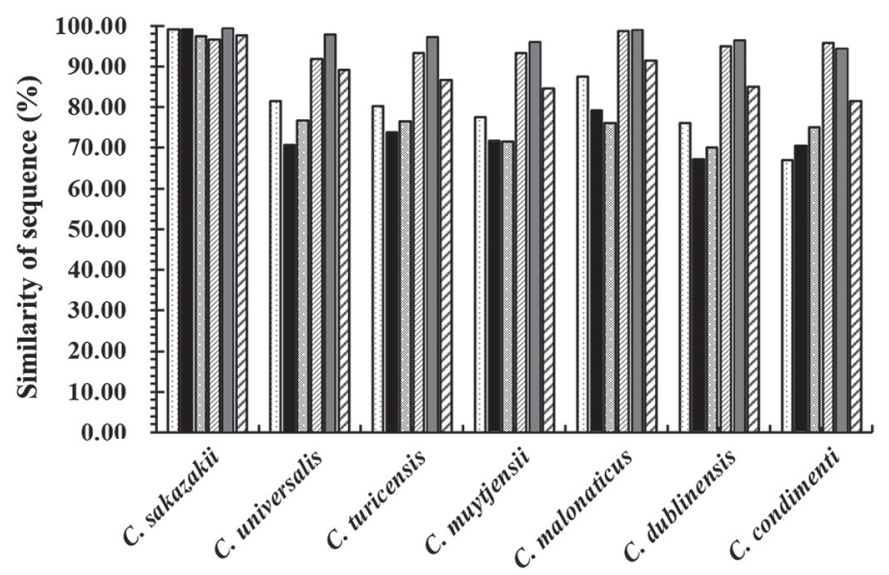

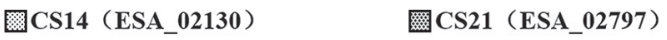
罷CS38（ESA_04347-ESA_04349）目SpeCronsaka（gyrB）
圈Csak (cgcA)

B

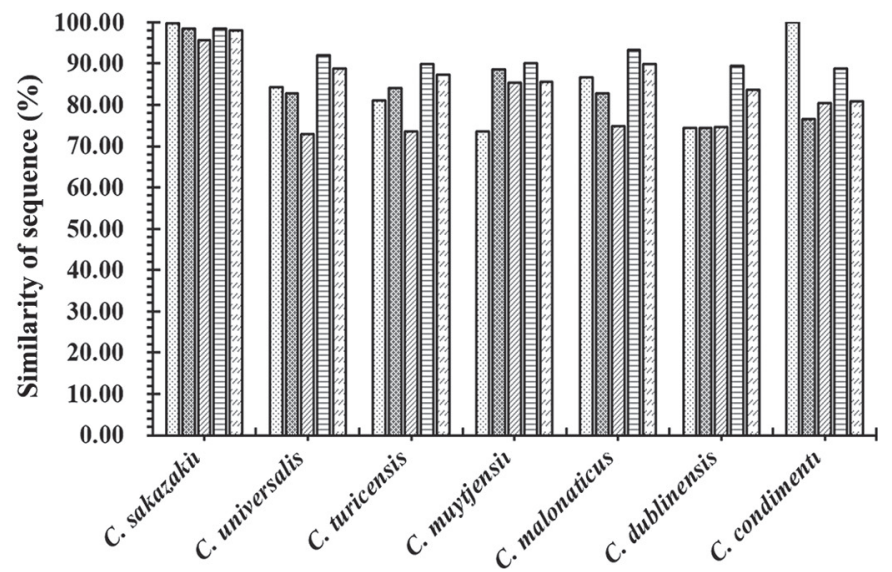

Figure 1. Similarity of DNA sequence within 7 species of Cronobacter. (A) Similarity of target gene sequences within 7 species of $C r o n o b a c t e r$; (B) similarity of the sequence of DNA fragments amplified by PCR using 5 primer sets within 7 species of Cronobacter.

which could be attributed to limitations in the sequence information in the NCBI GenBank database. Thus, it is necessary to verify the results of BLAST by performing PCR assays. The 3 primer sets were designated CS14, CS21, and CS38. The identities in GenBank of the genes they targeted were ESA_02130, ESA_02797, and ESA_04347-ESA_04349, respectively. The protein ESA_02797 encodes a membrane porin protein known as PapC. In another report, comparative genomic hybridization $(\mathrm{CGH})$ analysis showed that PapC was unique to C. sakazakii and absent in C. malonaticus, $C$. muytjensii, C. turicensis, and C. dublinensis (Kucerova et al., 2010). However, the proteins ESA_02130 and ESA_04347-ESA_04349 encode hypothetical proteins, and thus their function is still unknown.

The genes RpoB (Stoop et al., 2009), gyrB (Huang et al., 2013), and $c g c A$ (Carter et al., 2013), and the 3 genes (ESA_02130, ESA_02797 and ESA_04347ESA_04349) we screened were used to identify $C$. sakazakii. The sequences of the 6 genes of $C$. sakazakii ATCC BAA-894 were used as target and they were compared with 6 other species of Cronobacter using the tool provided by Cronobacter MLST Databases (http:// pubmlst.org/cronobacter/). One hundred thirty-five strains of C. sakazakii, 24 strains of C. malonaticus, 10 strains of C. turicensis, 2 strains of C. universalis, 13 strains of $C$. dublinensis, and 1 strain of $C$. condimenti were used in this alignment. The results showed that the 3 genes (ESA_02130, ESA_02797 and ESA_04347ESA_04349) we screened showed better specificity than genes in previous reports (Figure 1A). The specificity of $r p o B$ was lower and therefore, $2 \mathrm{PCR}$ reactions were needed to identify C. sakazakii. The primer sets (CS14, CS21, CS38, Csak, and SpeCronsaka) targeting the other 5 genes could identify C. sakazakii in one PCR reaction, and the DNA fragments amplified by PCR

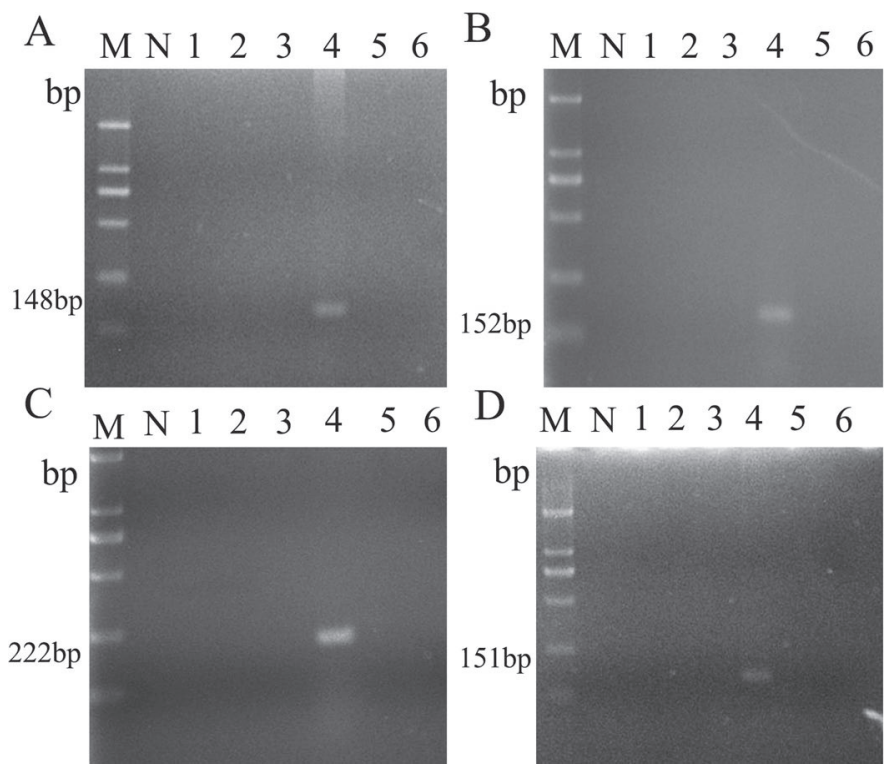

Figure 2. Results of PCR of genome DNA of the strains within the Cronobacter genus using primer sets CS14, CS21, and CS38. Lane $\mathrm{M}=D S^{\mathrm{TM}} 2000$ marker (Dongsheng Biotechnology, Guangdong, China); lane $\mathrm{N}=$ negative control (double-distilled $\mathrm{H}_{2} \mathrm{O}$ ); lanes 1-6: C. malonaticus DSM18702, C. turicensis DSM18703, C. dublinensis DSM18705, C. sakazakii CICC21560, C. muytjensii CICC21563, and C. universalis NCTC9529, respectively. (A) Primer set CS14; (B) primer set CS21; (C) primer set CS38; (D) primer set SpeCronsaka. All concentrations of genomic DNA were diluted to about $20 \mathrm{ng} / \mu \mathrm{L}$. 
A

a

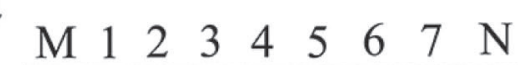

bp

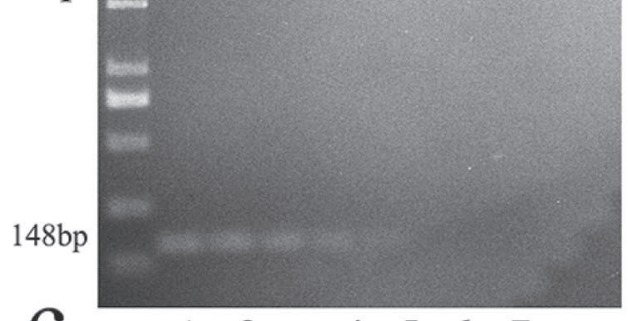

C $\begin{array}{llllllllll}\text { M } & 1 & 2 & 3 & 4 & 5 & 6 & 7 & \mathrm{~N}\end{array}$

bp

$\mathrm{p}$

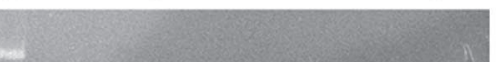

$22 \mathrm{bp}$

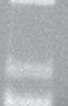

(and

p
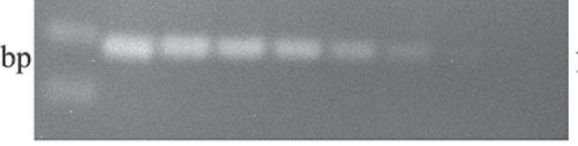

b

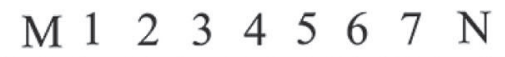

bp

-
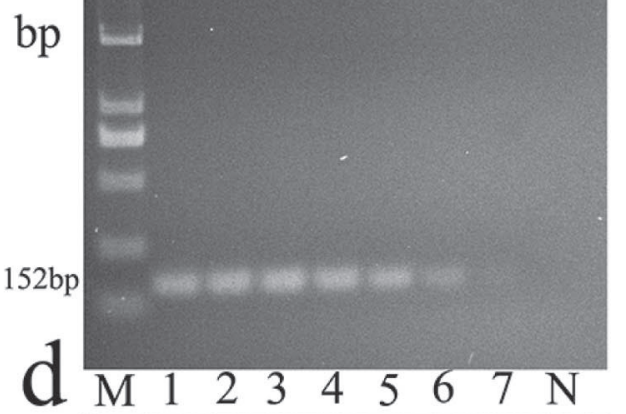

bp

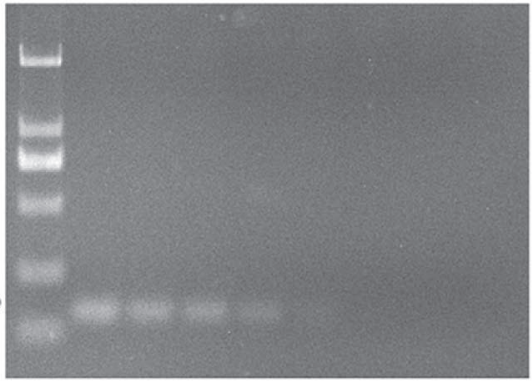

$151 \mathrm{bp}$

\section{B}

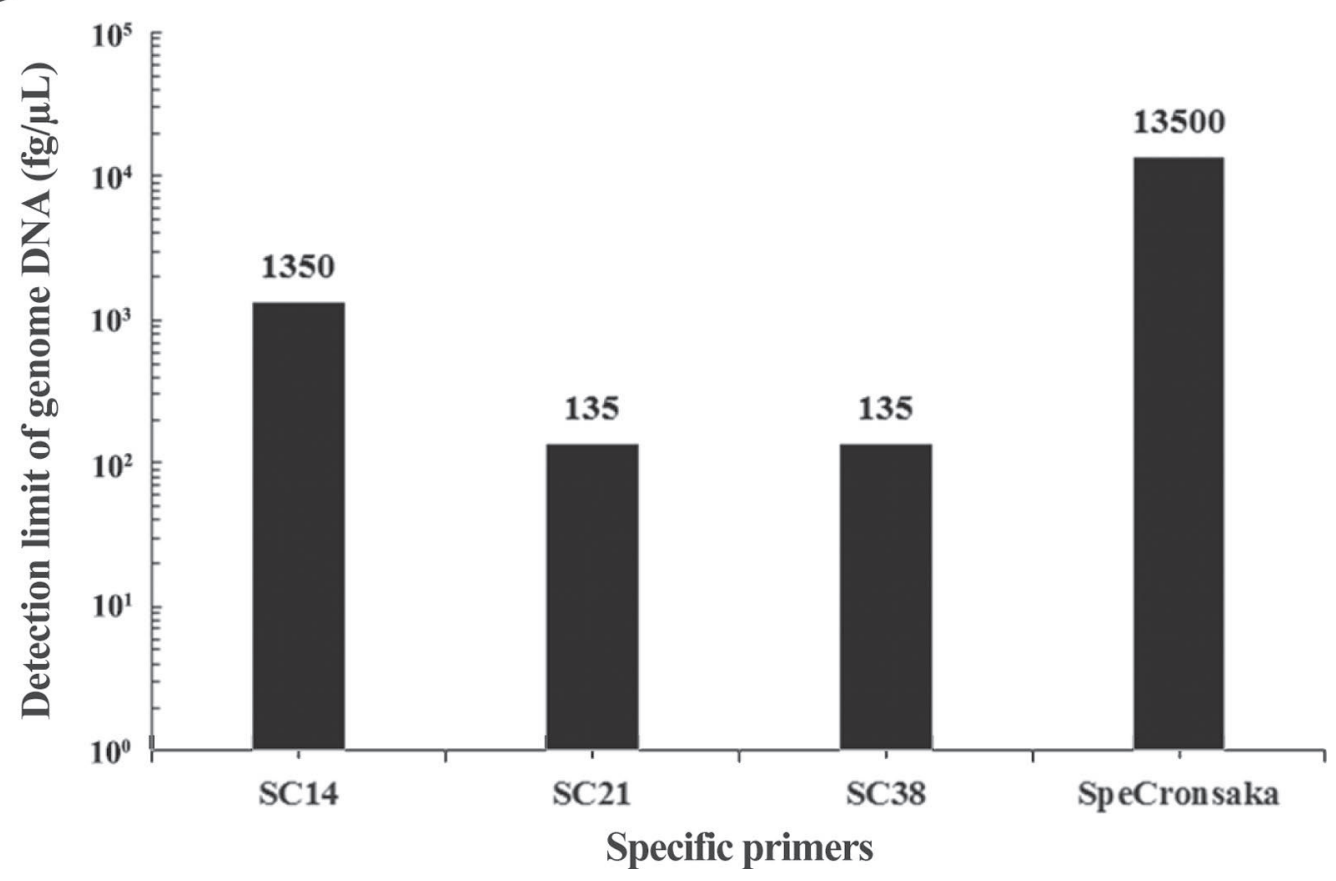

Figure 3. (A) PCR detection sensitivity using dilutions of genomic DNA from Cronobacter sakazakii CICC21560. Lane M $=$ DS ${ }^{\mathrm{TM}} 2000$ marker (Dongsheng Biotechnology, Guangdong, China); lane $\mathrm{N}=$ negative control (double-distilled $\mathrm{H}_{2} \mathrm{O}$ ); lanes $1-7=13.5 \mathrm{ng} / \mu \mathrm{L}, 1.35 \mathrm{ng} / \mu \mathrm{L}$, $135 \mathrm{pg} / \mu \mathrm{L}, 13.5 \mathrm{pg} / \mu \mathrm{L}, 1.35 \mathrm{pg} / \mu \mathrm{L}, 135 \mathrm{fg} / \mu \mathrm{L}$, and $13.5 \mathrm{fg} / \mu \mathrm{L}$, respectively. (a) Primer set CS14; (b) primer set CS21; (c) primer set CS38; (d) primer set SpeCronsaka. (B) Results of Figure 1A showing detection limits $(\mathrm{fg} / \mu \mathrm{L})$ of genomic DNA. 


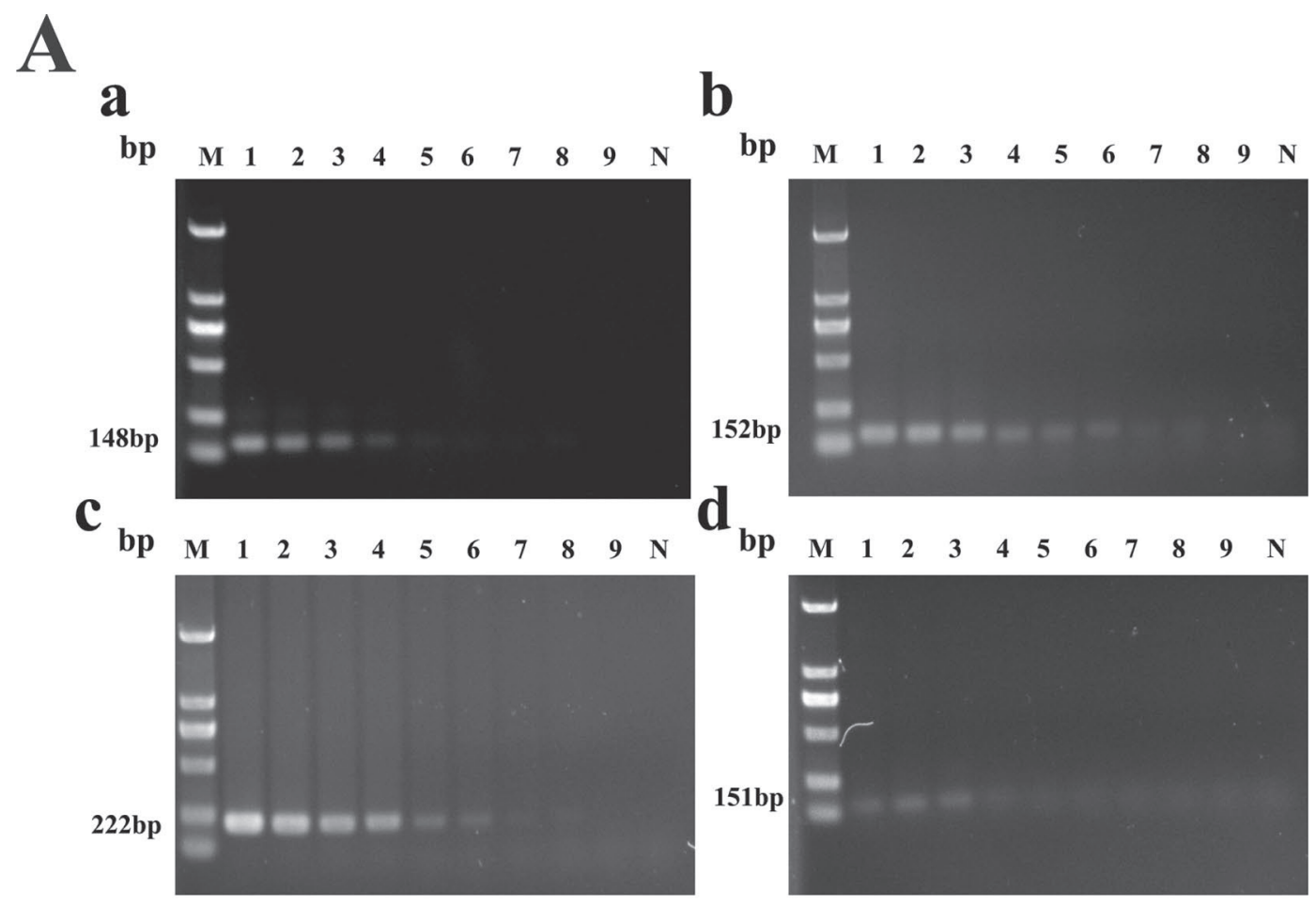

B

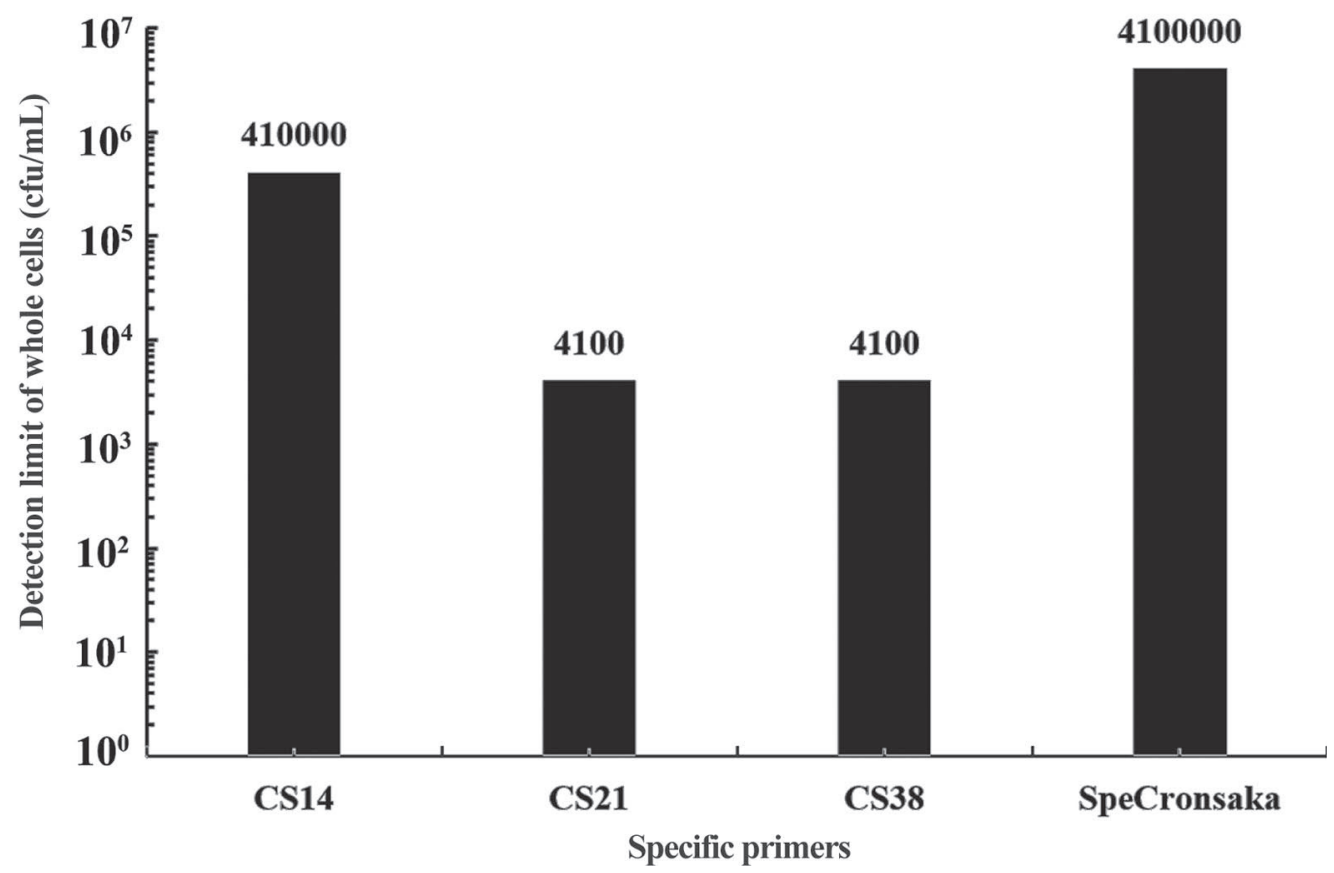

Figure 4. (A) PCR detection sensitivity using dilutions of a pure culture of Cronobacter sakazakii CICC21560. Lane M $=$ DS $S^{\mathrm{TM}} 2000$ marker (Dongsheng Biotechnology, Guangdong, China); lane $\mathrm{N}^{4}=$ negative control (double-distilled $\mathrm{H}_{2} \mathrm{O}$ ); lanes $1-9=4.1 \times 10^{8} \mathrm{cfu} / \mathrm{mL}, 4.1 \times 10^{7}$ $\mathrm{cfu} / \mathrm{mL}, 4.1 \times 10^{6} \mathrm{cfu} / \mathrm{mL}, 4.1 \times 10^{5} \mathrm{cfu} / \mathrm{mL}, 4.1 \times 10^{4} \mathrm{cfu} / \mathrm{mL}, 4.1 \times 10^{3} \mathrm{cfu} / \mathrm{mL}, 4.1 \times 10^{2} \mathrm{cfu} / \mathrm{mL}, 5.1 \times 10^{1} \mathrm{cfu} / \mathrm{mL}, 6.4 \times 10^{0} \mathrm{cfu} / \mathrm{mL}$, respectively. (a) Primer set CS14; (b) primer set CS21; (c) primer set CS38; (d) primer set SpeCronsaka. (B) Results of Figure 3A using whole cells showing detection limits $(\mathrm{cfu} / \mathrm{mL})$. 
using these primers were analyzed as well (Figure 1B). Our primer sets CS21 and CS38 showed better specificity than previous primers and primer set CS14.

Primer set SpeCronsaka target cgcA (Huang et al., 2013) was selected for comparison with the 3 primer sets, CS14, CS21 and CS38, designed in the current study. The PCR results of the 4 primer sets using DNA from 6 species within the Cronobacter genus showed that they were specific for C. sakazakii (Figure 2), showing one clear band, and thus indicating that the 4 primer sets were specific for C. sakazakii.

\section{Evaluation of Sensitivity of PCR Assays Using the Specific Primer Sets}

We determined the detection limit of the PCR assays using the 4 primer sets and different cell or DNA concentrations of $C$. sakazakii CICC2156. The detection limits using genomic DNA for the SpeCronsaka, CS14, CS21, and CS38 primer sets were $13.5 \mathrm{pg} / \mu \mathrm{L}$, $1.35 \mathrm{pg} / \mu \mathrm{L}, 135 \mathrm{fg} / \mu \mathrm{L}$, and $135 \mathrm{fg} / \mu \mathrm{L}$, respectively. Clearly, PCR assays using CS21 and CS38 primer sets were more sensitive than those using CS14 and SpeCronsaka primer sets (Figure 3), because the detection limit of PCR assays using these 2 primer sets was about 100 times greater compared with SpeCronsaka primers. Moreover, when using cells, the detection limit for SpeCronsaka, CS14, CS21, and CS38 primer sets were $4.1 \times 10^{6}, 4.1 \times 10^{5}, 4.1 \times 10^{3}$, and $4.1 \times 10^{3} \mathrm{cfu} / \mathrm{mL}$, respectively (Figure 4). The results were in agreement with the detection limits using different DNA concentrations, showing again that PCR assays using primer sets CS21 and CS38 were more sensitive than those using SpeCronsaka for the detection of C. sakazakii.

\section{Testing for PCR Interference and Specificity Using Various Concentrations of E. coli}

Food samples generally contain background microflora in addition to the contaminating pathogen, and DNA from these non-Cronobacter bacteria may affect PCR detection of C. sakazakii, leading to false-positive or false-negative results. Therefore, PCR interference using CS14, CS21, CS38, and SpeCronsaka primers was evaluated with a mixture of DNA from C. sakazakii and E. coli cells. As shown in Figure 5, only one target band appeared even with a cell concentration of $E$. coli up to $10^{8} \mathrm{cfu} / \mathrm{mL}$, indicating that the 4 primer sets were not affected by DNA from other bacteria (E. coli in this case).

\section{Application of the New Primer Sets in PCR Assays for Detection C. Sakazakii in Artificially Contaminated PIF}

Artificially contaminated PIF was used to evaluate the sensitivity, specificity, and reliability of the primer sets CS14, CS21, CS38, and SpeCronsaka. The cell concentrations of $C$. sakazakii added to PIF were 5.5 $\times 10^{1}, 5.5 \times 10^{0}$, and $5.5 \times 10^{-1} \mathrm{cfu} / 10 \mathrm{~g}$ of PIF. As shown in Table 3, PCR assays using primer sets CS14 and SpeCronsaka could not detect C. sakazakii because of their lower sensitivity, even after $12 \mathrm{~h}$ of enrichment. However, C. sakazakii was detected using PCR assays with primer sets CS21 and CS38 after $8 \mathrm{~h}$ of enrichment. The detection limit was $5.5 \times 10^{-1} \mathrm{cfu} / 10 \mathrm{~g}$ of PIF after $8 \mathrm{~h}$ of enrichment. Therefore, detection of $C$. sakazakii by PCR in PIF can be accomplished within $11 \mathrm{~h}$.

Table 3. Results of PCR (positive, +, or negative, -) of powdered infant formula (PIF) samples artificially contaminated with Cronobacter sakazakii

\begin{tabular}{|c|c|c|c|c|c|c|c|c|}
\hline \multirow[b]{2}{*}{ Primer } & \multirow{2}{*}{$\begin{array}{l}\text { C. sakazakii } \\
\text { concentration } \\
\text { (cfu/10 g) }\end{array}$} & \multicolumn{7}{|c|}{ Enrichment time } \\
\hline & & $0 \mathrm{~h}$ & $2 \mathrm{~h}$ & $4 \mathrm{~h}$ & $6 \mathrm{~h}$ & $8 \mathrm{~h}$ & $10 \mathrm{~h}$ & $12 \mathrm{~h}$ \\
\hline \multirow[t]{4}{*}{ CS14 } & $5.5 \times 10^{-1}$ & - & - & - & - & - & - & - \\
\hline & $5.5 \times 10^{0}$ & - & - & - & - & - & - & - \\
\hline & $5.5 \times 10^{1}$ & - & - & - & - & - & - & - \\
\hline & Control check & - & - & - & - & - & - & - \\
\hline \multirow[t]{4}{*}{ CS21 } & $5.5 \times 10^{-1}$ & - & - & - & - & + & + & + \\
\hline & $5.5 \times 10^{0}$ & - & - & - & - & + & + & + \\
\hline & $5.5 \times 10^{1}$ & - & - & - & - & + & + & + \\
\hline & Control check & - & - & - & - & - & - & - \\
\hline \multirow[t]{4}{*}{ CS38 } & $5.5 \times 10^{-1}$ & - & - & - & - & + & + & + \\
\hline & $5.5 \times 10^{0}$ & - & - & - & - & + & + & + \\
\hline & $5.5 \times 10^{1}$ & - & - & - & - & + & + & + \\
\hline & Control check & - & - & - & - & - & - & - \\
\hline \multirow[t]{4}{*}{ SpeCronsaka } & $5.5 \times 10^{-1}$ & - & - & - & - & - & - & - \\
\hline & $5.5 \times 10^{0}$ & - & - & - & - & - & - & - \\
\hline & $5.5 \times 10^{1}$ & - & - & - & - & - & - & - \\
\hline & Control check & - & - & - & - & - & - & - \\
\hline
\end{tabular}




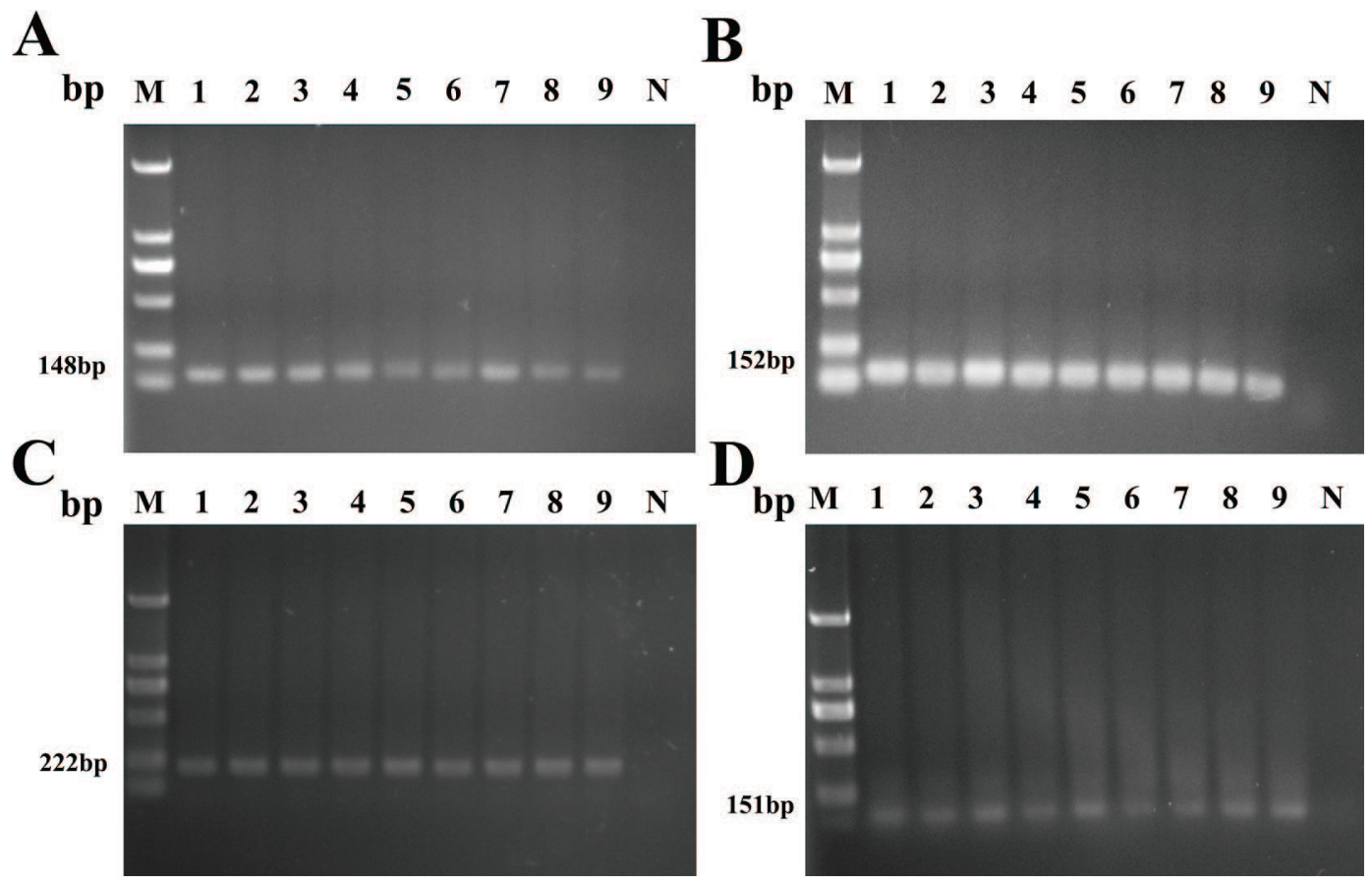

Figure 5. Results of PCR assays using primers targeting Cronobacter sakazakii testing for interference with different concentrations of E. coli DNA. Lane $\mathrm{M}=D S^{\mathrm{TM}} 2000$ marker (Dongsheng Biotechnology, Guangdong, China); lane $\mathrm{N}$ = negative control (double-distilled $\mathrm{H}_{2} \mathrm{O}$ ); lanes 1-9 $=$ mixtures of C. sakazakii CICC21560 (concentration fixed at $10^{7} \mathrm{cfu} / \mathrm{mL}$ ) and Escherichia coli CMCC23657 at $10^{8}, 10^{7}, 10^{6}, 10^{5}, 10^{4}, 10^{3}, 10^{2}$, $10^{1}$, and $10^{0} \mathrm{cfu} / \mathrm{mL}$, respectively. (A) Primer set 14; (B) primer set CS21; (C) primer set CS38; (D) primer set SpeCronsaka.

\section{CONCLUSIONS}

In this study, 38 DNA fragments that were specific for C. sakazakii were identified from the complete genome sequence of C. sakazakii ATCC BAA-944, and PCR primers were designed for these fragments. After screening all of the primers, 2 primer sets, CS21 and CS38, targeting the ESA_02797 and ESA_04347ESA_04349 genes, were found to be more specific, more sensitive, and more reliable than the other designed primers and a primer set reported previously in PCR assays. Use of the 2 primer sets in PCR assays to detect C. sakazakii in artificially contaminated PIF showed that the detection limit reached $5.5 \times 10^{-1} \mathrm{cfu} / 10 \mathrm{~g}$ of PIF after $8 \mathrm{~h}$ of enrichment. To our knowledge, this is the first report using these 2 gene targets for PCR detection of C. sakazakii in food.

\section{ACKNOWLEDGMENTS}

The work was supported by the Agricultural Science and Technology Innovation Fund of Jiangsu Province [China; CX(12)3087] and development program of Jiangsu Province (BE2011782). We thank Pina M. Fratamico (USDA, Agricultural Research Service, Eastern Regional Research Center, Wyndmoor, PA) for her help in revising this manuscript.

\section{REFERENCES}

Arseni, A., E. Malamou-Ladas, C. Koutsia, M. Xanthou, and E. Trikka. 1987. Outbreak of colonization of neonates with Enterobacter sakazakii. J. Hosp. Infect. 9:143-150.

Carter, L., L. A. Lindsey, C. J. Grim, V. Sathyamoorthy, K. G. Jarvis, G. Gopinath, C. Lee, J. A. Sadowski, L. Trach, M. Pava-Ripoll, B. A. McCardell, B. D. Tall, and L. Hu. 2013. Multiplex PCR assay targeting a diguanylate cyclase-encoding gene, $c g c A$, to differentiate species within the genus Cronobacter. Appl. Environ. Microbiol. 79:734-737.

Derzelle, S., F. Dilasser, V. Maladen, N. Soudrie, A. Leclercq, B. Lombard, and V. Lafarge. 2007. Comparison of three chromogenic media and evaluation of two molecular-based identification systems for the detection of Enterobacter sakazakii from environmental samples from infant formulae factories. J. Food Prot. 70:16781684 .

Friedemann, M. 2007. Enterobacter sakazakii in food and beverages (other than infant formula and milk powder). Int. J. Food Microbiol. 116:1-10.

Hassan, A. A., O. Akineden, C. Kress, S. Estuningsih, E. Schneider, and E. Usleber. 2007. Characterization of the gene encoding the 16S rRNA of Enterobacter sakazakii and development of a speciesspecific PCR method. Int. J. Food Microbiol. 116:214-220.

Healy, B., S. Cooney, S. O'Brien, C. Iversen, P. Whyte, J. Nally, J. J. Callanan, and S. Fanning. 2010. Cronobacter (Enterobacter sakazakii): An opportunistic foodborne pathogen. Foodborne Pathog. Dis. 7:339-350.

Hoque, A., T. Ahmed, M. Shahidullah, A. Hossain, A. Mannan, K. Noor, K. Nahar, M. Ilias, and D. Ahmed. 2010. Isolation and molecular identification of Cronobacter spp. from powdered infant formula (PIF) in Bangladesh. Int. J. Food Microbiol. 142:375-378.

Huang, C.-H., M.-T. Chang, and L. Huang. 2013. Use of novel speciesspecific PCR primers targeted to DNA gyrase subunit B $($ gyrB) 
gene for species identification of the Cronobacter sakazakii and Cronobacter dublinensis. Mol. Cell. Probes 27:15-18.

Iversen, C., A. Lehner, N. Mullane, J. Marugg, S. Fanning, R. Stephan, and H. Joosten. 2007. Identification of "Cronobacter" spp. (Enterobacter sakazakii). J. Clin. Microbiol. 45:3814-3816.

Iversen, C., N. Mullane, B. McCardell, B. D. Tall, A. Lehner, S. Fanning, R. Stephan, and H. Joosten. 2008. Cronobacter gen. nov., a new genus to accommodate the biogroups of Enterobacter sakazakii, and proposal of Cronobacter sakazakii gen. nov., comb. nov., Cronobacter malonaticus sp. nov., Cronobacter turicensis sp. nov., Cronobacter muytjensii sp. nov., Cronobacter dublinensis sp. nov., Cronobacter genomospecies 1, and of three subspecies, Cronobacter dublinensis ssp. dublinensis ssp. nov., Cronobacter dublinensis ssp. lausannensis ssp. nov. and Cronobacter dublinensis ssp. lactaridi ssp. nov. Int. J. Syst. Evol. Microbiol. 58:1442-1447.

Iversen, C., M. Waddington, S. L. On, and S. Forsythe. 2004. Identification and phylogeny of Enterobacter sakazakii relative to Enterobacter and Citrobacter species. J. Clin. Microbiol. 42:5368-5370.

Jackson, E. E., H. Sonbol, N. Masood, and S. J. Forsythe. 2014. Genotypic and phenotypic characteristics of Cronobacter species, with particular attention to the newly reclassified species Cronobacter helveticus, Cronobacter pulveris, and Cronobacter zurichensis. Food Microbiol. 44:226-235.

Jaradat, Z. W., Q. O. Ababneh, I. M. Saadoun, N. A. Samara, and A. M. Rashdan. 2009. Isolation of Cronobacter spp. (formerly Enterobacter sakazakii) from infant food, herbs and environmental samples and the subsequent identification and confirmation of the isolates using biochemical, chromogenic assays, PCR and $16 \mathrm{~S}$ rRNA sequencing. BMC Microbiol. 9:225.

Jarvis, K. G., C. J. Grim, A. A. Franco, G. Gopinath, V. Sathyamoorthy, L. Hu, J. A. Sadowski, C. S. Lee, and B. D. Tall. 2011. Molecular characterization of Cronobacter lipopolysaccharide Oantigen gene clusters and development of serotype-specific PCR assays. Appl. Environ. Microbiol. 77:4017-4026.

Joseph, S., and S. J. Forsythe. 2012. Insights into the emergent bacterial pathogen Cronobacter spp., generated by multilocus sequence typing and analysis. Front. Microbiol. 3:397.

Kucerova, E., S. W. Clifton, X. Q. Xia, F. Long, S. Porwollik, L. Fulton, C. Fronick, P. Minx, K. Kyung, W. Warren, R. Fulton, D. Feng, A. Wollam, N. Shah, V. Bhonagiri, W. E. Nash, K. Hallsworth-Pepin, R. K. Wilson, M. McClelland, and S. J. Forsythe. 2010. Genome sequence of Cronobacter sakazakii BAA-894 and comparative genomic hybridization analysis with other Cronobacter species. PLoS ONE 5:e9556.

Li, Y., L. Cao, J. Zhao, Q. Cheng, F. Lu, X. Bie, and Z. Lu. 2012. Use of $\mathrm{rpoB}$ gene sequence analysis for phylogenetic identification of Cronobacter species. J. Microbiol. Methods 88:316-318.
Li, Y., Q. Chen, J. Zhao, H. Jiang, F. Lu, X. Bie, and Z. Lu. 2014. Isolation, identification and antimicrobial resistance of Cronobacter spp. isolated from various foods in China. Food Contr. 37:109-114.

Liu, Y., X. Cai, X. Zhang, Q. Gao, X. Yang, Z. Zheng, M. Luo, and X. Huang. 2006. Real time PCR using TaqMan and SYBR Green for detection of Enterobacter sakazakii in infant formula. J. Microbiol. Methods 65:21-31.

Mohan Nair, M. K., and K. S. Venkitanarayanan. 2006. Cloning and sequencing of the ompA gene of Enterobacter sakazakii and development of an ompA-targeted PCR for rapid detection of Enterobacter sakazakii in infant formula. Appl. Environ. Microbiol. $72: 2539-2546$

Mullane, N., P. O'Gaora, J. E. Nally, C. Iversen, P. Whyte, P. G. Wall, and S. Fanning. 2008. Molecular analysis of the Enterobacter sakazakii O-antigen gene locus. Appl. Environ. Microbiol. 74:3783-3794.

Muytjens, H. L., H. C. Zanen, H. J. Sonderkamp, L. A. Kollee, I. K. Wachsmuth, and J. J. Farmer 3rd.. 1983. Analysis of eight cases of neonatal meningitis and sepsis due to Enterobacter sakazakii. J. Clin. Microbiol. 18:115-120.

Ray, P., A. Das, V. Gautam, N. Jain, A. Narang, and M. Sharma. 2007. Enterobacter sakazakii in infants: novel phenomenon in India. Indian J. Med. Microbiol. 25:408-410.

Seo, K. H., and R. E. Brackett. 2005. Rapid, specific detection of Enterobacter sakazakii in infant formula using a real-time PCR assay J. Food Prot. 68:59-63.

Simmons, B. P., M. S. Gelfand, M. Haas, L. Metts, and J. Ferguson. 1989. Enterobacter sakazakii infections in neonates associated with intrinsic contamination of a powdered infant formula. Infect. Contr. Hosp. Epidemiol. 10:398-401.

Stoop, B., A. Lehner, C. Iversen, S. Fanning, and R. Stephan. 2009 Development and evaluation of rpoB based PCR systems to differentiate the six proposed species within the genus Cronobacter. Int. J. Food Microbiol. 136:165-168.

Townsend, S., E. Hurrell, and S. Forsythe. 2008. Virulence studies of Enterobacter sakazakii isolates associated with a neonatal intensive care unit outbreak. BMC Microbiol. 8:64.

Zimmermann, J., H. Schmidt, M. J. Loessner, and A. Weiss. 2014 Development of a rapid detection system for opportunistic pathogenic Cronobacter spp. in powdered milk products. Food Microbiol. 42:19-25. 